OPEN ACCESS

Edited by:

Fook-Choe Cheah,

National University of

Malaysia, Malaysia

Reviewed by:

Marion Aw,

National University of

Singapore, Singapore

Qianshen Zhang,

University of Hong Kong, China

Erin Ross,

University of Colorado Boulder,

United States

*Correspondence:

Chantal Lau

clau@bcm.edu

Specialty section:

This article was submitted to Neonatology,

a section of the journal

Frontiers in Pediatrics

Received: 14 March 2020

Accepted: 11 May 2020

Published: 09 June 2020

Citation:

Lau C (2020) To Individualize the

Management Care of High-Risk Infants With Oral Feeding Challenges:

What Do We Know? What Can We

Do? Front. Pediatr. 8:296

doi: 10.3389/fped.2020.00296

\section{To Individualize the Management Care of High-Risk Infants With Oral Feeding Challenges: What Do We Know? What Can We Do?}

\author{
Chantal Lau* \\ Department of Pediatrics, Baylor College of Medicine, Houston, TX, United States
}

The increase in preterm infants' survival over the last 30 years has shed light over their inability to feed by mouth safely and efficiently. With adverse events such as increased risks for oxygen desaturation, bradycardia, penetration/aspiration, infants' hospitalization in neonatal intensive care units (NICUs) are understandably prolonged. Unfortunately, this leads to delayed mother-infant reunion, maternal stress, breastfeeding obstacles, and increased medical costs. Such impediments have stimulated clinicians and researchers to better understand the underlying causes and develop evidence-based solutions to assist these infants. However, it is notable that the research-to-practice translation of this knowledge has been limited as there are still no validated guidelines or protocols as how to best diagnose and care for these infants. This report revisits the immature physiologic functions at the root of these infants' oral feeding difficulties, the current practices, and the recent availability of evidence-based efficacious tools and interventions. Taking advantage of the latter, it presents a renewed perspective of how management strategies can be tailored to the specific needs of individual patients.

Keywords: evidence-based practice, feeding monitors, feeding tools, feeding guidelines, research-to-practice translation, feeding efficiency and safety, prematurity and low birth weight

\section{INTRODUCTION}

Oral feeding difficulties in children is a subtle condition that is not a well-recognized public concern. It has been reported that $20-50 \%$ of healthy developing children encounter such complications $(1,2)$. This incidence can rise to $80 \%$ for children with developmental disabilities and complex medical conditions, such as prematurity, cerebral palsy (https://.asha.org/PRPSpecificTopic.aspx? folderid $=8589934965 \&$ section $=$ Incidence_and_Prevalence). In a recent study of moderate preterm infants $\left[29^{0 / 7}-33^{6 / 7}\right.$ weeks gestational age (GA)] from 18 sites within the NICHD Neonatal Research Network, "inadequate oral feeding" was the most prevalent barrier to hospital discharge. Of the $56 \%(3,376 / 6,017)$ of infants who remained hospitalized until 36 weeks postmenstrual age (PMA), 37\% (1,262 infants) were clinically stable "feeders and growers" whose only delayed discharge was due to inadequate oral feeding performance (3). 
In neonatal intensive care units (NICUs), as the survival of infants born prematurely increased, it has come to light that for many of them, attainment of independent oral feeding is a struggle leading to prolonged hospitalization, while increasing maternal stress and medical cost (3-5). Such condition is often followed by re-hospitalization or visits to feeding disorder clinics as our current knowledge-based practice for the care of these infants has not kept up with their increased survival (5-8). This is reflected by the lack of validated and structured oral feeding guidelines at how to best manage these issues and the large variations in practices between hospitals $(3,9-11)$. As attainment of independent oral feeding is one of the three criteria infants need to meet prior to home discharge (5), the faster they can wean from tube feeding safely and efficiently, the sooner they can be reunited with their mothers. Such accomplishment is based on their ability to complete all their feedings (breast or bottle) with no adverse events, e.g., oxygen desaturation, bradycardia, within an allotted period of time, e.g., 20-30 min to avoid excessive energy expenditure, while demonstrating appropriate weight gain, e.g., $\sim 15 \mathrm{~g} / \mathrm{kg} /$ day.

The purpose of this report is to present a review of the current practices and the efficacious research tools/interventions developed over the last two decades shown to shorten time to safe and efficient attainment of infant independent oral feeding. In combining this research knowledge with current clinical practices, a novel feeding management plan/guidelines catered specifically to the care of individual infants in NICUs is presented.

\section{WHAT DO WE KNOW?}

\section{Immature Physiologic Functions Are at the Root of Preterm Infants' Oral Feeding Difficulties}

Generally, in clinical practice, the evaluation of a particular patient's condition(s) begins by conducting a differential diagnosis based on the systematic review of possible causes before his/her management plan is developed. However, it was not until the survival of preterm infants in NICUs increased that healthcare providers' concern over infant oral feeding difficulties came to light. As such there was a limited understanding of the neurophysiologic and -motor components implicated in their ability to feed by mouth. This led to an increased interest in understanding the maturation of their oral feeding skills and in the development of tools and therapies to assist these young patients more readily wean from tube feeding. It is following the development of the oro-motor kinetic monitoring (OMK) technology that our laboratory began to understand the complex involvement of the different neuro-motor and -physiologic functions required for these infants to feed safely and efficiently (12-16).

At present, for infants with oral feeding challenges, the focus has been primarily on infants' ability to suck, swallow, and breathe. However, amiss in this rationale is the role of the esophageal function $(17,18)$. Indeed, the transport of a bolus from the mouth to the stomach involves two elements that independently ensure efficiency and safety. Efficiency relates to the proper coordination of the phases of the Swallow Process; namely, the formation of the bolus during the oral phase, its swift transport through the pharynx during the pharyngeal phase, and through the esophagus during the esophageal phase (19). Safety in swallowing, for infants as well as adults, relates to the proper timing of respiratory inhalation/exhalation during the pharyngeal phase of swallowing to prevent $\mathrm{O}_{2}$ desaturation and/or liquid aspiration/penetration into the lungs during inhalation $(20,21)$. The difficulty in diagnosing the origin(s) of oral feeding difficulties results from the fact that uncoordinated or improper execution at any phase of the Swallow Process can lead to the same visual adverse responses shown in Figure 1, e.g., drooling, poor lip seal, oxygen desaturation, pulling away, and feeding aversion. Consequently, based on the commonality of behaviors demonstrated by infants during oral feeding and the lack of appropriate tools to properly monitor the functionality of each phase of the Swallow Process and respiration, it is difficult for caregivers, as observers, to identify the cause(s) responsible for the onset of such events. It is for this reason that the current knowledge-based management plans devised by feeding therapists for bottle- and breast-feeders, i.e., occupational therapists, speech language pathologists, lactation consultants, raise concerns among their multi-disciplinary team members whose viewpoints understandably are influenced by their respective professional training and expertise. Additionally, consensus for best practice is often challenged by the use of qualitative/descriptive over quantitative/objective approaches. This is particularly germane when any resulting benefit may simply be due to infants' normal maturation (22). Other significant factors also impact preterm infants' oral feeding performance. Their abrupt transition from an in-utero to exutero environment forces them to adapt to conditions that they are not developmentally prepared for, e.g., bright lights, loud sounds, varying temperatures, unsupported forced postures (10). As basic physiologic/behavioral/organizational functions, e.g., sleep/awake, calm/agitated, mature at different times, studies have shown that exposure to such variety of NICU stressors has been correlated with changes in infant brain structures and functions $(23,24)$. In brief, the multitude of maturational and environmental factors that lead preterm infants to exhibit similar adverse events during oral feeding makes it is difficult to identify the culprit(s) at the origin of their oral feeding difficulties.

\section{Current Knowledge-Based Practice Guidelines, Tools, and Interventions}

When advancement of infant oral feeding in NICUs is hampered, feeding therapists are commonly consulted $(19,25,26)$. Due to the lack of available devices to monitor infants' sucking skills, non-nutritive assessment follows standardized plan based on visual and sensory feedback whether infants are bottle- or breastfeeding. Using a gloved finger, therapists assess the anatomical development of infants' oral structures, e.g., hard/soft palate, gum line, and lingual mobility, e.g., lateralization, cupping, stripping. As the infant is sucking on the therapist's gloved finger, functional development is assessed by visual and tactile feedback, i.e., watching the movement and coordination of cheeks, jaws, and lip seal around the finger, the relative rhythmicity of pressure 


\section{Examples of Common “Visual” Adverse Events during Nutritive Sucking}

- Poor lip seal

- Choking

- Drooling

- Pulling away from feeding

- O2 Desaturation

- Aspiration/Penetration

- Reflux/Vomit

- Feeding Aversion

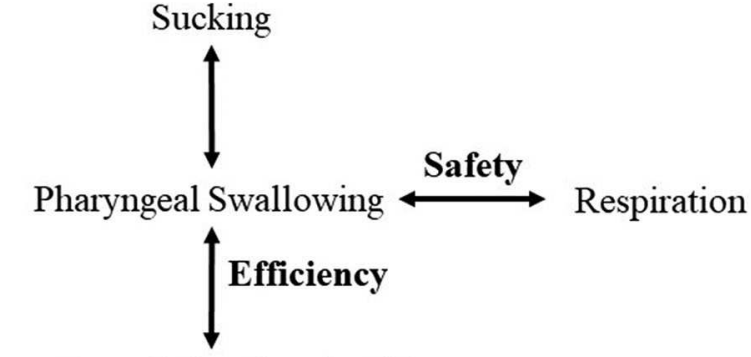

Esophageal aboral Peristalsis

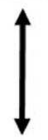

Stomach

FIGURE 1 | Commonality of "visual" adverse responses caused by untimely events at any level of the Swallow Process.

forces applied on the finger, and respiratory bursts/pauses. Evaluation of nutritive sucking skills conducted during bottle feeding is based on similar visual assessment of cheeks, jaws, lips, and the relative coordination of suck, swallow, and respiration while watching for any adverse events, e.g., choking, $\mathrm{O}_{2}$ desaturation, pushing back (12). As infant organization/states or external factors such as NICU surroundings, may interfere with performance, a management plan that encompasses the above concerns is proposed that may include varied perioral stimulations, e.g., cheek and chin support, pacing, non-nutritive oral motor stimulation (NNOMT), adjusting feeding positions, e.g., sidelying vs. semi-reclined, dimming overhead lights, etc. $(10,27,28)$. In recent years, responsive/cue-based/“infant driven feeding" approaches have grown in popularity. However, in the absence of data providing strong evidence of study design stringencies, a recent Cochrane Intervention Review recommended that "a large RCT [randomized controlled trial] would be needed to confirm "their benefits and determine if such approach may affect other important [preterm infants'] outcomes" $(29,30)$. When flow rate during bottle feeding is deemed too slow or too fast, it is normally addressed by changing nipples claimed to be slower/faster as per manufacturers (31-34). Insofar as caregivers' decisions are subjective and use trial and error approaches, at times, there lacks a general consensus among the multi-disciplinary members of the NICU team regarding best treatment $(27,28,35,36)$.

The health benefits gained by mothers and infants through breastfeeding are no longer disputed (37-40). In addition to the nutritional advantage mother's milk offers over artificial formulae, breastfeeding is the optimal nurturance infants can receive from their mother through their close physical contact. Indeed, a mother's balanced nutritional and maternal care will benefit her child's not only nutritionally, but also nonnutritionally in the provision of appropriate stimulation of their infants' maturing neuro-physiologic/-motor/-behavioral functions (41-46). Breastfeeding challenges for NICU infants has similarly increased the demand for lactation consultants. Evaluation for breastfeeding difficulties assesses maternal factors e.g., nipple shape, degree of elasticity/protractility as they may interfere with infant's performance and ability to latch-on and remain latched-on during a feeding (6). As breastfeeding requires the involvement of both mother and infant, when infant breastfeeding difficulties arise, any evaluation requires not only assessment of infant oral feeding skills, but just as importantly the lactation performance of their mother. It remains unclear whether a mother's mammary development and function is affected by her shortened gestation. Lactation may be impaired not only by milk supply and milk release during breastfeeding, but also by mother's motivation to breastfeed, her overall wellbeing, and stress $(41,47)$. It is well-acknowledged that stress can interfere with the neuro-endocrine regulation of lactation both at the level of milk synthesis and milk release/ejection $(6,41,46)$. Although a number of breastfeeding assessment scales have been developed based on a variety of infant behavioral criteria, they are not yet well-recognized (48-53). This situation is similar to that of feeding therapists' evaluation of infant's bottle-feeding difficulties as lactation consultants' feedback lack objective evidence-based studies supporting their proposed treatment(s). Nevertheless, the broad variety of current knowledge-based bottle and breastfeeding approaches proposed by feeding therapists underscores "the importance of strategies for stimulation of [infant] sensory-motor-oral system to decrease the period of transition to full oral feeding system" (35).

\section{Novel Research Tools/Interventions}

A small number of devices have been developed to monitor infant non-nutritive and nutritive sucking. As described on their respective website, the NTrainer system (innarahealth.com) 
specifically monitors infants' non-nutritive suck and has developed non-nutritive assessments and therapies that "have been proven to reduce time to full oral feeding [...] and length of stay [...] in the NICU1." The NFANT ${ }^{\circledR}$ Sensor (nfant.com) monitors infant lingual movements during feeding and assist clinicians to "quickly determine optimal feeding parameters through objective metrics" using their Nfant Feeding Solution and Analytics. The Medoff-Cooper Nutritive Sucking Apparatus (M-CNSA) is a research tool that monitors sucking pressure (54).

Due to the commonality of the "visual" adverse symptoms that arise from dysfunctionality(ies) at the various levels of the Swallow Process (Figure 1), our approach attempted to examine the proper functionality at these levels. As our intention was first to specifically understand the development of infant nutritive sucking, our studies were conducted during bottle- rather than breast-feeding as the impact of any maternal inputs through their behavior and milk availability would obligatorily add noncontrollable external variables that would not be indicative of their infants' true competence. As infants comorbidities, e.g., bronchopulmonary dysplasia, post necrotizing enterocolitis, could interfere with infants oral feeding performance, our subjects were recruited from clinically stable very low birth weight (VLBW) preterm infants, i.e., "feeders and growers," whose discharge from NICUs were only delayed due to their inability to adequately feed by mouth $(3,13)$. Following the development of the oro-motor kinetic monitoring (OMK) technology, we gained a substantial understanding of the maturation of VLBW infants' nutritive and non-nutritive sucking and how appropriate synchronization of suck-swallow-breathe was necessary to ensure safe and efficacious oral feeding. With the understanding gained from the OMK technology, the development of additional tools and interventions naturally followed.

\section{The Oro-Motor Kinetic Monitoring Device (OMK) Technology \\ The OMK Nutritive Assessment Strategy (OMK-NS)}

To follow the natural development of infant nutritive sucking, the OMK-NS was developed using miniature sensors appropriately placed on the bottle nipple. As such, it can directly monitor the shape/form and strength ( $\mathrm{mmHg}$ ) of the two components of sucking, i.e., Suction and Expression (55). Suction corresponds to the negative intra-oral pressure generated with the closing of the nasal passages by the soft palate and lowering of the jaw that draws milk into the mouth, similar to drinking from a straw. Expression, in turn, corresponds to the compression and stripping of the nipple by the tongue against the hard palate to eject milk into the mouth. With this device, we described five stages of nutritive sucking (NS) maturation based on the presence/absence of suction, expression, their respective rhythmicity, and synchronization with one another (16). We have also shown that this technology can be readily adapted to the breast nipple during breastfeeding.

To simultaneously monitor the sucking-swallowing-breathing events during bottle feeding, two drums placed over the hyoid and diaphragm allowed for the capture the pharyngeal swallow reflex and respiratory effort (56), respectively. This provided evidence for the importance of the proper temporal coordination of sucking, swallowing, and respiratory functions $(14,16,57,58)$. If connected to infants' vital signs monitors, Figure 2 shows how one can monitor at the same time infants' clinical status.

The clinical importance of pediatric esophageal dysphagia is well-recognized by pediatric gastroenterologists (59). As the gastrointestinal (GI) system of the pig is the closest to that of the human (60), we conducted a study on preterm piglets using a 4-port "multi-channel" esophageal catheter provided by our co-author (Omari T) and obtained evidence supporting the importance of the proper maturation of esophageal peristalsis as another essential component for the safe and swift transport of a bolus from the oral cavity to the stomach (17). Preterm piglets demonstrated similar susceptibility to necrotizing enterocolitis and oral feeding issues as their human counterparts, e.g., milk leakage, regurgitation, limited endurance, inability to complete a feeding. When compared to healthy term piglets, the occurrence of the mature pattern of aboral propagating peristaltic waves for bolus transport, i.e., from upper esophageal sphincter to stomach, was significantly less frequent and of slower velocity (17). The development of monitoring devices has been problematic due to infants' fragility and small sizes. However, devices for the assessment of esophageal function, using high resolution manometry with and without impedance (HRIM/HRM) are becoming adaptable to the pediatric population (61-65).

\section{The OMK Non-nutritive Assessment Strategy (OMK-NNS)}

The OMK technology can be adapted for non-nutritive sucking assessment on a pacifier or a disposable glove as used by feeding therapists for their consults, providing objective quantitative measures similar to those obtained during nutritive sucking (OMK-NS) e.g., pressure force $(\mathrm{mmHg})$ of suction and expression, NNS frequency, shape/form of these two components, duration of pauses and sucking bursts that cannot be identified otherwise $(10,12,13)$. It is advanced that if used for the preliminary clinical evaluation of infant oral feeding skills, therapists' recommendations based on objective outcome measures would be more readily accepted by their NICU team members than currently viewed. Of value, the OMK-glove may be a valuable tool for the objective training of new feeding therapists as they can learn to interpret the variations of their sensory feedback from the recordings obtained. With the OMK technology, we confirmed that nutritive sucking occurs at 1 cps vs. that of non-nutritive sucking at $2 \mathrm{cps}$ (66). This is a useful means to help determine if milk release is occurring when infants are nutritively vs. non-utritively sucking on the breast. When thickeners are added to formula/breastmilk during bottle feeding to decrease reflux, they may occlude the nipple hole preventing milk outflow. This can be readily recognized if infants begin sucking non-nutritively at 2 cps. Of interest, we have observed that infants' non-nutritive sucking is already mature by the time oral feeding is initiated. This implies that the oromotor competence to generate suction and expression is already attained (12). For this reason, the observation of "rhythmic" sucking on a pacifier/finger is incorrectly used as an index of readiness to feed. 


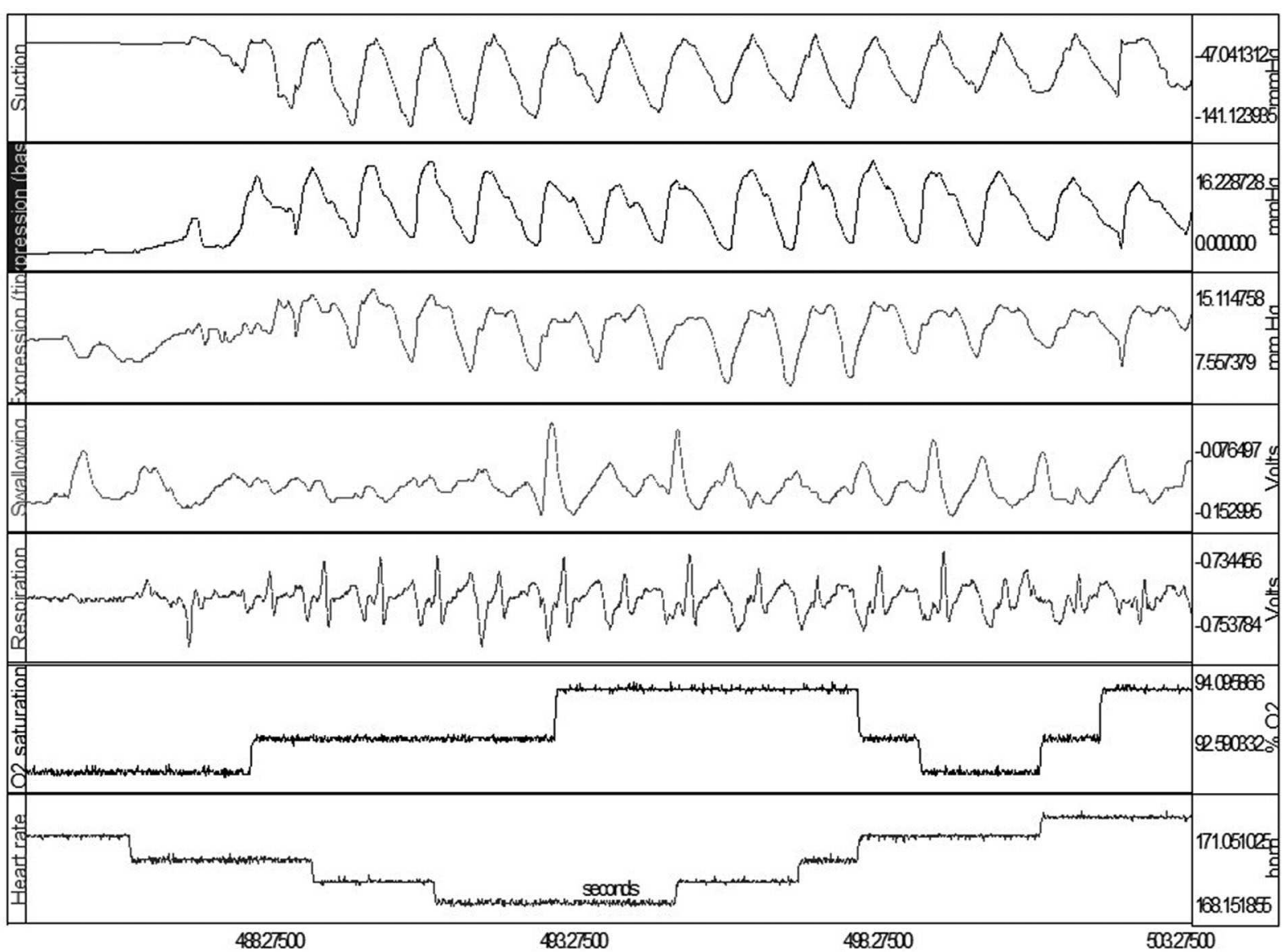

FIGURE 2 | Simultaneous OMK-NS monitoring of nutritive sucking, i.e., suction, expression (base and tip), swallow, respiration, $\mathrm{O}_{2}$ saturation, heart rate. Note: Expression monitored at base and tip of tongue for assessment of lingual mobility, e.g., compression, stripping.

\section{The Oral Feeding Skills Scale (OFS)}

The Oral Feeding Skills scale (OFS) is a 4-level clinical scale developed as a simple objective indicator of infants' feeding ability. It has the unique advantage that it does not require any special device, only the recording of the percent volume taken over volume prescribed during the first $5 \mathrm{~min}$ of a feeding ("proficiency") and the rate of milk transfer ( $\mathrm{ml} / \mathrm{min}$ ) over an entire feeding ("endurance"). The OFS assessment presumes that prior to all oral feedings, infants are left undisturbed $30 \mathrm{~min}$ prior in order to ensure minimal fatigue before they are fed. As shown in Figure 3A, proficiency on the $X$-axis is used as an estimate of infant's "true" feeding skills as fatigue is minimal. Rate of milk transfer on the $Y$-axis is used as an index of endurance or how fatigue impacts an infant's overall feeding performance (67). Four levels of OFS skills are delineated by cut-offs of proficiency set at $30 \%$ and "endurance" at $1.5 \mathrm{ml} / \mathrm{min}$ for VLBW infants (67), and $40 \%$ and $1.5 \mathrm{ml} / \mathrm{min}$ for late preterm, respectively (68). These four OFS levels distinguish proficiency (true feeding skills) and endurance levels as "high" or "low." Figure 3B presents the levels of these two measures at each OFS levels, I-IV, and their correlation with infant overall feeding performance or overall transfer, i.e., percent volume taken/volume prescribed at a feeding. A significant correlation was observed between each OFS levels and \% overall transfer (67). It is of interest to note that OFS levels II and III show that proficiency and endurance, on their own, have equal impact on overall transfer [ 80\%; Figure 3B]. Potential interventions comprising "targeted interventions" and "endurance training" to assist infants when tested at these individual OFS levels are based on their respective proficiency and endurance (Figure 3B). Figure 3C confirms that preterm infants can demonstrate the whole range of OFS levels I-IV when monitored at their first oral feeding (67). This would explain why, as caregivers, we are familiar with the disparity that infants of same GA and PMA may show broad ranges of oral feeding aptitudes.

The OFS scale offers several advantages: (1) It can be used at any feeding with no special device and without interfering with infant's task because taking a reading of the volume taken at $\sim 5$ min into a feeding coincides with an initial recommended "burping" pause. (2) As it is correlated positively with infants' $\%$ overall transfer during a feeding (Figure 3B), it becomes an objective index of the correlation between infants' oral feeding skills and performance over time. (3) The observation that infants of similar GA monitored at similar PMA demonstrate all four 


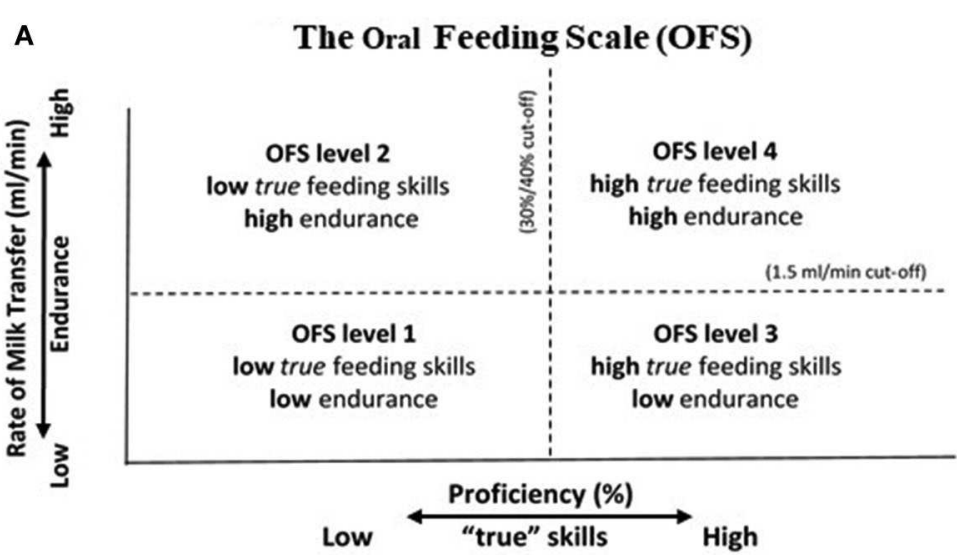

B OFS Scale Interpretations \& Clinical Validation

\begin{tabular}{|c|c|c|c|c|}
\hline $\begin{array}{c}\text { OFS } \\
\text { Levels }\end{array}$ & $\begin{array}{c}\text { Feeding } \\
\text { skills } \\
\text { (Pro) }\end{array}$ & $\begin{array}{c}\text { Endurance } \\
\text { (RT) }\end{array}$ & $\begin{array}{c}\text { Overall } \\
\text { Transfer } \\
\text { (\%) }\end{array}$ & Potential Interventions \\
\hline I & low & low & $\sim 30 \%$ & $\begin{array}{c}\text { Targeted Intervention(s) } \\
\text { \& } \\
\text { endurance training }\end{array}$ \\
\hline II & low & high & $\sim 80 \%$ & Targeted Intervention(s) \\
\hline III & high & low & $\sim 80 \%$ & endurance training \\
\hline IV & high & high & $\sim 100 \%$ & none \\
\hline
\end{tabular}

C_OFS Levels@1 $1^{\text {st }}$ oral feeding

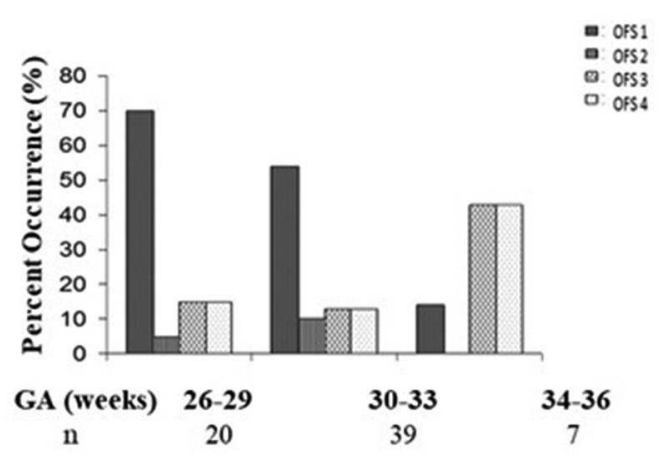

FIGURE 3 | (A) The four OFS levels delineated by: Proficiency on the $X$-axis at 30 and $40 \%$ for VLBW and late preterm, respectively; Endurance on the $Y$-axis at 1.5 $\mathrm{ml} / \mathrm{min}$. (B) Interpretations and Clinical Validation of the OFS Levels, Feeding Skills (Pro: proficiency), Endurance (RT: rate of milk transfer), Overall transfer (\% volume taken/volume to be taken), Potential targeted interventions for the respective "low" levels at each OFS levels (see Figure 5). (C) Percent occurrence of OFS levels (I-IV) in three groups of infants born at 26-29, 30-33, and 34-36 weeks GA at their first oral feeding ( 35 weeks PMA); n: number of subjects/group. Note: broad variations of OFS levels at each GA.

OFS levels confirms that their oral feeding skills mature at different rates (Figure 3C). As such, care should be taken not to interpret that infants falling below "expectation" are delayed. (4) With the ability to monitor the maturational progress of an individual infant's proficiency and endurance, the OFS offers the opportunity to differentiate the impact that the maturation of "true" skills (proficiency) and fatigue/endurance can have on infant overall performance (10). Consequently, infants' OFS levels are better indicators of oral feeding competence than the use of PMA or aptitude to suck on a pacifier. (5) The efficacy of an intervention on a particular infant can be verified as it would be reflected by improved OFS level along with corresponding oral feeding performance (10). Providers need to remember that if a particular intervention is not beneficial for one infant, it can be for another as the cause of their respective dysphagia may lie at different levels of the Swallow Process. (6) Finally, when used in patient rounds, the 4-level OFS scale offers team members an objective/quantitative feedback of a patient's performance over time that the current subjective/descriptive approaches cannot, e.g., "baby fed well," "poorly," "better/worse than the day before." Due to its objective feedback, the OFS scale has been adopted into patient's medical records in some hospitals as well as in research.

\section{The Infant Self-Pacing (ISP) Feeding Bottle}

The principles of the ISP bottle eliminate two properties of fluid physics that occur within a rigid standard bottle as it empties when an infant is feeding. As a standard bottle empties during a feeding, a natural increase in internal vacuum build-up occurs hindering fluid outflow. This leads infants to suck harder to first overcome the internal vacuum before obtaining milk, likely increasing unnecessary energy expenditure (Figure 4A). The positive hydrostatic pressure exerted by milk over the nipple hole when a bottle is tilted naturally leads to a disruptive "milk drip" whether the baby is sucking or not (69) (Figure 4B). With 


\section{A}

\section{Vacuum build-up withing a standard bottle during feeding}
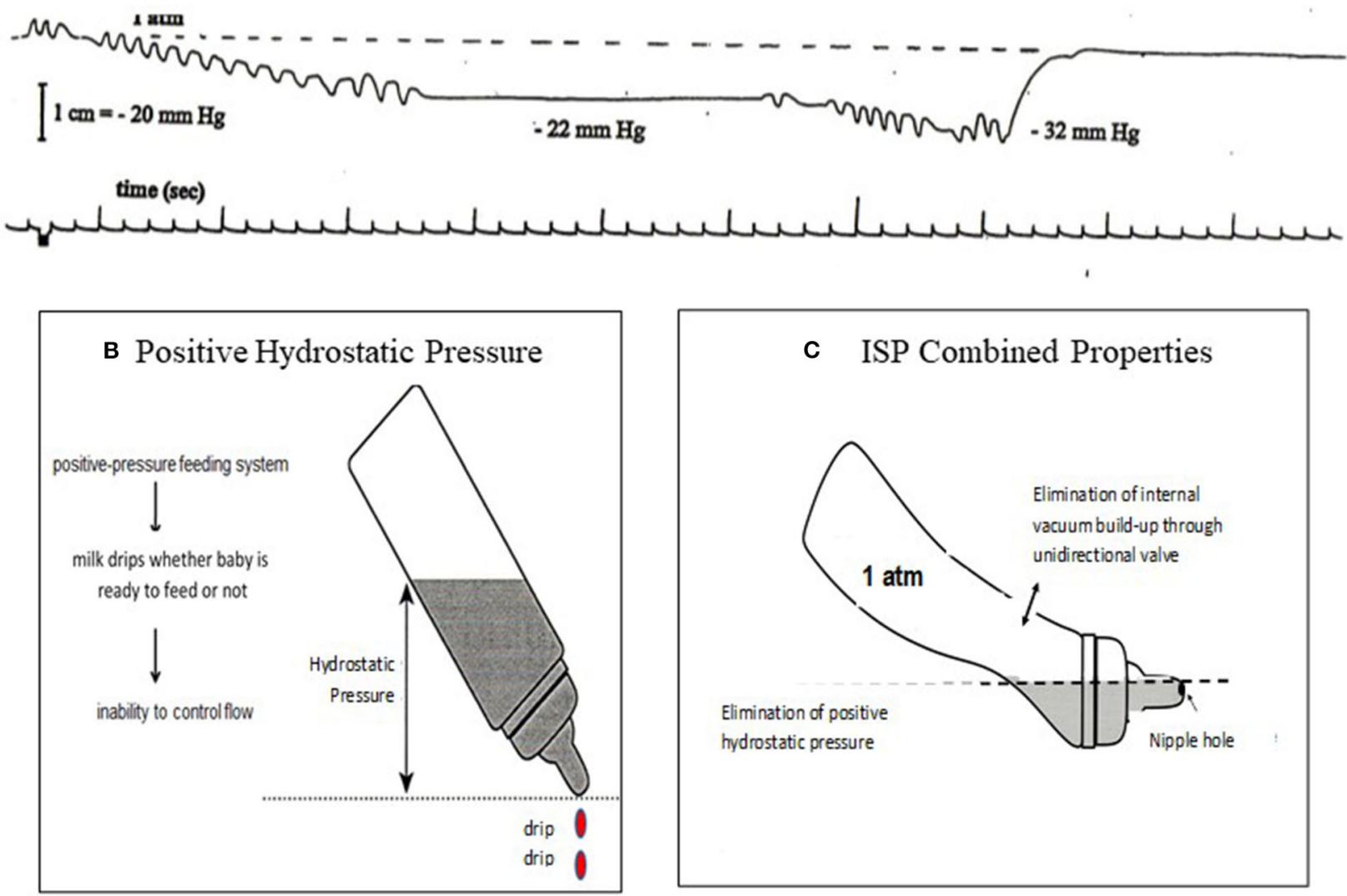

FIGURE 4 | (A) Internal vacuum build-up from $1 \mathrm{~atm}(0 \mathrm{mmHg})$ to $-22 \mathrm{mmHg}$ after first sucking burst maintained as infant did not release the nipple, decreasing to $-32 \mathrm{mmHg}$ after a second sucking burst. Infant would need to generate a sucking force $>32 \mathrm{mmHg}$ in order to obtain milk. (B) a positive hydrostatic pressure over a nipple hole leads to a natural outflow (drip) whether infant is sucking or not. (C) ISP principles: Elimination of internal vacuum and hydrostatic pressure over nipple hole gives infants control over their own feeding.

the elimination of the natural internal negative pressure buildup after each suck and "milk drip" (Figure 4C), the control of the feeding is given to the infant and not the caregiver because the infant does not need to suck harder (preserving energy) to overcome the increasing internal negative pressure and can pause to rest/catch-up breathing whenever needed without milk dripping in his/her mouth. Although the volume of a milk "drip" may not appear of significance, it should be noted that the average bolus size of VLBW infants average $0.14 \pm 0.06 \mathrm{ml}$ when they transition from tube to independent oral feeding. This is significantly less than the $0.22 \pm 0.07 \mathrm{ml}$ monitored in full term infants during their first 2 weeks of life (14).

In general, bottle feeding is controlled by caregivers who, through visual and auditory sensory feedback, determine whether a feeding ought to be maintained or stopped. Unless obvious adverse events occur, e.g., turning blue, pushing away, triggered hospital alarms, the feeding is continued. Caregivers may take different approaches in "assisting" their infant's feeding such as increasing/decreasing milk outflow by using fast or slow flow nipples, offering softer/harder nipples, providing "encouragement" to complete a feeding, or stopping the feeding because infant appears satiated. Under such circumstances, it is unclear the bases upon which such rationales arise because without appropriate devices, we know that immature neuromotor/-physiologic events cannot be readily detected, e.g., dyscoordination of suck-swallow-respiration-esophageal motility, silent penetration/aspiration, non-overt gastro-esophageal reflux.

To our knowledge, the ISP is the only feeding bottle that gives control of the feeding to the babies. Whenever needed, e.g., rest, catch-up breathing, it allows them to stop with the bottle in the mouth without being overwhelmed as milk drip is also eliminated. This assumes no caregivers' inputs during feedings. With the ISP, we observed that a greater percentile of infants completed their feeding with no adverse events. This was achieved at a faster rate while using a more mature OFS level than control counterparts feeding from a standard bottle $(69,70)$. Therefore, we speculate that infants, with normally developing central nervous system, are able to reflexively regulate their nutritive sucking in the absence of external controlling factors. This assumption is based on anatomical evidence that 
the respiratory, sucking, and swallowing centers are anatomically in close proximity from each other in the brainstem, with separate pools of motor neurons implicated in their respective sequential rhythmic movements and regulated by central pattern generators (CPGs) $(71,72)$. The existence of an intrinsic "tau $(\tau)$ " guide acting as a common processor that links timing events of different motor movements has been proposed (7375). A similar theory of cross-system interactions between suck, swallow, and respiration has been advanced to explain the ability of these functions to rapidly re-adjust to variations occurring at any one of these levels during oral feeding (76). The essential integrity of sensory afferents signaling changes in physiologic and environmental functions has also been proposed for the proper regulatory feedback of these individual functions (77).

From such understanding, the following tools along with evidence-based tested interventions we developed are described below.

\section{Interventions That Enhance Infants' Oral Feeding Aptitude}

Infant oral feeding performance does not solely relate to the proper maturation of infants' oral feeding skills. Their clinical status, behavioral states, infant's organization, and environmental conditions at feeding time are well-known contributors to a successful feeding (6). Oral feeding is optimized when infants are in drowsy/alert inactive, quiet awake, and/or alert state as defined by the Newborn Individualized Developmental Care and Assessment Program (NIDCAP) (7880). As mentioned earlier, environmental conditions such as bright light, loud surroundings, fluctuating temperatures, infant unsupported posture are disruptive $(10,81)$. Consequently, the development of any intervention needs to encompass not only uni-modal approaches targeting physiologic functions, e.g., sucking, swallowing, respiration, esophageal function, but also multi-modal approaches that encompass the above "deterrent" factors. Provision of multi-sensory stimulations to offset these negative factors are varied and have focused on tactile, auditory, and olfactory senses, e.g., skin-to-skin holding/kangaroo care, infant massage/tactile-kinesthetic, music therapy, maternal pheromones. Except for the benefits of the well-acknowledged skin-to-skin holding $(82,83)$, music and massage therapy along with maternal pheromones will require further confirmation (84-86). We examined the potential benefits of some of these interventions on infant oral feeding difficulties as few of them have been used for this purpose. The OFS scale was used as an index of oral feeding skills, while days from initiation to independent oral feeding was used as index of oral feeding performance. We demonstrated the benefits of a specific nonnutritive oral motor training protocol (NNOMT) and a swallow exercise directed at sucking and swallowing, respectively $(10,87-$ 89). The use of a protocol consisting of active non-nutritive sucking on a pacifier that followed the same schedule as that of the NNOMT did not replicate the benefit observed with the latter (89). As the general benefits of infant massage for infants and parents are well-recognized $(90,91)$, we verified its beneficial effect on preterm infants' oral feeding using the massage protocol developed by Field for preterm infants (92).
This intervention was similarly effective on improving infants' OFS levels and accelerating their attainment of independent oral feeding (87). Over the years, various infant feeding positions have been advocated as "optimal," e.g., the customary semireclined (control), upright, and sidelying. As each lacks evidencebased support, we examined VLBW infants' performance when fed under these three conditions. No statistical difference in transition time from tube to independent oral feeding was observed (28). It should be noted that no infants in the above studies demonstrated any adverse events during their feedings.

From a common sense approach, as poor endurance is commonly linked to poor feeding performance, "endurance training" is suggested whereby a feeding duration is stopped when the infant shows signs of fatigue, e.g., increased pauses, changes in organization or state, rather than "encouraging" the infant to continue. For instance, if an infant is following a regimen of 2 oral feedings/day (20 min/feeding), but cannot continue after $10 \mathrm{~min}$, a revised schedule of 4 oral feedings/day (10 $\mathrm{min} /$ feeding) regimen may be more appropriate and advantageous. Indeed, one may reason that the duration of "practice" time is the same, i.e., $40 \mathrm{~min} /$ day, but training during these $40 \mathrm{~min}$ in the latter case occurs at a time when the infant has greatest endurance. This principle addresses the common saying that "practice makes perfect" as long as the practice duration remains productive. This premise is based on the appreciation that brain plasticity can reorganize sensorimotor areas following beneficial and detrimental practices (93, 94). Consequently, to optimize beneficial sensory inputs, if fatigue were recognized and oral feeding regimen were revised accordingly, detrimental consequences such as oral feeding aversion, regurgitation, aspiration/penetration, may be reduced. Along this line of reasoning, it is proposed that the ISP bottle may be considered an appropriate intervention as it gives control of the feeding to the infants. With control of flow rate and pauses, infants would experience optimal sensory inputs.

\section{WHAT CAN WE DO?}

\section{Flexible Individualized Management Guidelines}

Customarily, the evidence-based efficacy of any intervention on a particular population is confirmed by following appropriately designed studies or randomized clinical trials using appropriate statistical approaches. However, as the functional maturation profiles of preterm infants of same GA and PMA are not uniform, as shown in Figure 3C, one ought not presume that if an intervention does not demonstrate statistical efficacy for a group of infants, that it cannot be efficacious for some of them. Insofar as the care of healthcare providers is directed toward individual patients, it is advanced that the ease-of-use of the OFS scale can help identify individual infants who do or do not benefit from a particular intervention. A fitting example relates to our earlier study on "optimal" feeding positions wherein no statistical difference in transition time from tube to independent oral feeding was observed between positions (28). If the OFS scale had been used to follow individual infants' progress as they 


\section{Potential Approaches for Individual infants}

\section{Overall Transfer $\geq 80 \%$ and/or OFS level IV $\rightarrow$ allow for Self-Maturation}

If Overall Transfer $<80 \%$ and/or $<$ OFS level IV, the following interventions may be considered
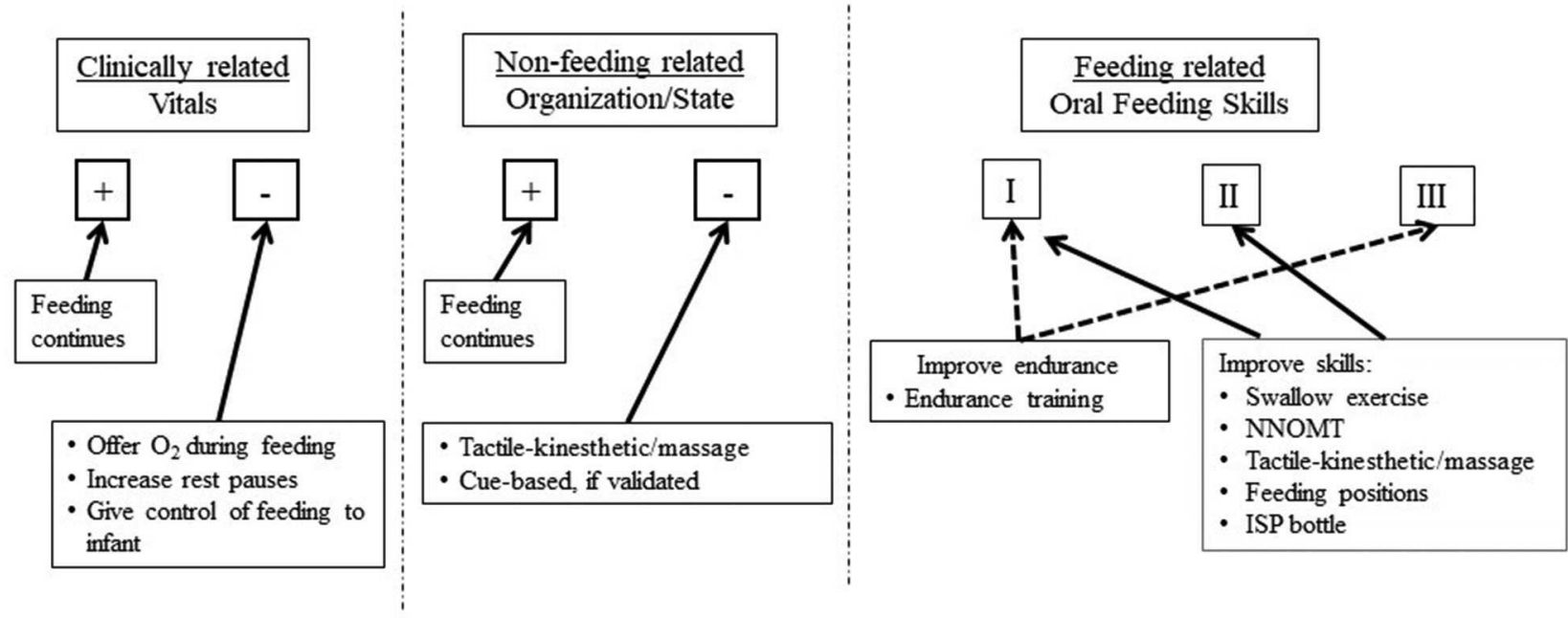

FIGURE 5 | Proposed approaches based on individual infant's challenges, i.e., Clinically related, Non-feeding related, Feeding related; (+) Adequate, (-) Inadequate; OFS levels I, II, III.

transition from tube to independent oral feeding, identification of the ones who did and did not benefit from being fed semireclined, upright, or sidelying could have been identified. As such, one of the advantages of the OFS scale is to allow close monitoring of the efficacy of any intervention on individual infants $(10,89)$. It is based on the simplicity of use of the OFS scale that the individualized management protocol below is presented. This approach is similar to the one used by feeding therapists in the development of their management plans with the advantage that monitoring performance with the OFS scale will provide objective outcome measures that have been shown to correlate with proficiency, endurance, oral feeding skills, and performance (Figures 3A,B).

Consequently, it is advanced that the routine use of the OFS scale will allow caregivers to closely monitor the oral feeding skills of their individual patients. The guidelines described below make use of a "research-to-practice" translation to complement the current clinical practices. Although we do not know the initial causes of individual infants' dysphagia, we do know that they may arise from their clinical status, non-feeding, and feeding related factors, e.g., $\mathrm{O}_{2}$ desaturation, behavioral organization/state, immature oral feeding skills, respectively. For each of these three categories, there are evidence-based beneficial interventions available as presented earlier (Figure 5). Proficiency can be used as an estimate of infants' nutritive sucking ability when fatigue is minimal, while rate of milk transfer can be used as an estimate of infants' endurance as a function of their clinical status, behavioral organization/state, and/or stress (95-99). Thus, considering all the factors that may impact preterm infants' ability in attaining independent oral feeding, Figures 5, 6 are proposed targeted interventions and general guidelines that may be considered in the management plans of individual NICU infants. As the quality of their feeding performance is primarily measured clinically by their \% overall transfer, Figure 5 proposes that with overall transfer $\geq 80 \%$ or OFS level IV, no interventions are proposed to allow for infant "self-maturation." With overall transfer $<80 \%$ and/or OFS I-III, interventions may be offered to support infants' feeding performance based on their clinically related vitals, non-feeding related organization/state, and/or feeding skills as assessed by their OFS levels. Under each of these categories, targeted interventions are proposed based on clinical practices and objective evidence-based studies presented earlier. In regard to feeding related factors, proposed interventions are based on the interpretation of the OFS levels presented in Figure 3B.

Figure 6 is a suggested flexible algorithm using the OFS scale as the "monitoring device." The protocol calls for "reassessments" in 2-day block of times to allow for infants "self-maturation." This 2-day block window is based on our clinical observations that some infants, on their own, can show improvement in their oral feeding aptitude within 2 days in the absence of any interventions. Two paths are described. At a feeding therapist's initial bottle feeding consult, if infants demonstrate an OFS level IV and/or overall transfer $\geq 80 \%$ (Path I), progression of oral 


\section{Evidence-based Tools/Interventions:}

\section{- ISP bottle}

- Non-nutritive oral motor training (NNOMT)

- Swallow exercise

- Tactile-Kinesthetic/massage

- Feeding Positions

$---\rightarrow$ Interventions

offered in 2-day blocks to

allow for self maturation

\begin{tabular}{|l}
\hline yes \\
no \\
no effect after 2 days \\
(may consider two 2-dayblocks)
\end{tabular}

\section{Flexible Individualized Guidelines}

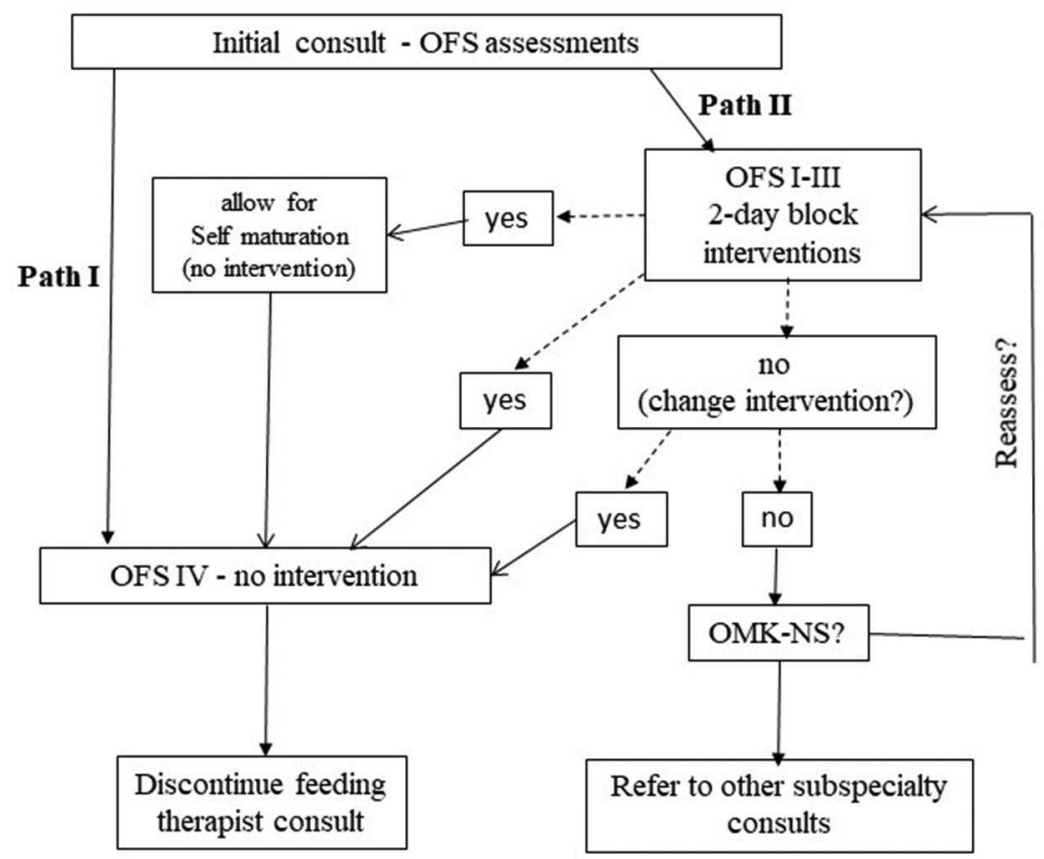

FIGURE 6 | Flexible individualized guidelines based on OFS levels; Path I for OFS level IV and Overall Transfer > 80\%; Path II for OFS level I to III and Overall Transfer $<80 \%$; interventions provided in 2-day blocks; (yes) positive effect; (no) no effect after 2-day block (see text for details).

feeding would be based on the provider/team's recommendation in oral feeding advancement with no needed intervention. With OFS levels I to III or overall transfer $<80 \%$ (Path II), infants will be offered targeted interventions listed in Figure 5 based upon their clinical stability, organization/state, and/or OFS skill levels. It should be reminded that monitoring infants' OFS levels requires minimal effort as proficiency can be computed at any feeding session by simply measuring the volume taken during the first $5 \mathrm{~min}$ at a "burping" pause in addition to the overall transfer and feeding duration that are customarily collected by caregivers. Daily intervention frequency and duration can be offered based on individual infants' clinical status, e.g., 15 $\mathrm{min} /$ day and reassessed in 2-day blocks. If a positive effect is observed in either OFS levels or \% overall transfer, infant can be moved into path I when OFS level IV or overall performance $\geq 80 \%$ is achieved. If no progress is observed after two 2-day blocks, i.e., 4 days of intervention, a change in intervention may be appropriate as the earlier intervention may not have targeted the appropriate level of the Swallow Process. An assessment using the OMK-NS monitoring system may be recommended in order to directly assess the maturation stage of infants' nutritive skills and suck-swallow-respiratory coordination if necessary. Referral to other pediatric subspecialties, e.g., Pediatric Ear Nose and Throat, Gastroenterology, Pulmonology, Cardiology, may be recommended. Any regression in oral feeding performance would naturally require further medical examination as it may be due to "yet" undetected clinical issues, e.g., sepsis, GI issues, silent gastro-esophageal reflex. The "flexibility" of the proposed guidelines is based on the recognition that due to the broad variations in preterm infants' developmental profiles, caregivers ought to remain flexible in the management plans they devise.

As mentioned above, the focus placed on bottle feeding described in our work does not reflect any partiality for bottleover breast-feeding, but rather a first step at understanding the development of infants' own skills in the absence of any potential maternal input(s) that may occur during breastfeeding, e.g., poor lactation, maternal own comfort to breastfeeding, infant proper attachment to the nipple-areolar complex. The OFS assessments in the NICU does not threaten infants' breastfeeding opportunities as most infants who are primarily breastfeeding are bottle fed when mother is not present. In fact, their OFS levels may help parents and caregivers identify potential breastfeeding difficulties resulting from infant's proficiency and endurance (Figure 3A). One may speculate that improvement of these infants' OFS levels may also lead to improved breastfeeding skills, e.g., latching-on, and earlier breastfeeding success.

Insofar as our tools and intervention programs can be readily used by healthcare providers in hospitals as well as out-patient settings, it is advanced that their adoption in clinics could provide a "Continuum of Care" approach that would allow "feeders and growers" to be discharged earlier from NICU and reduce medical costs, as such care can be readily assumed by out-patient services offering the same oral feeding management protocol.

In brief, the intent of these proposed flexible guidelines is to introduce to clinicians the evidence-based beneficial tools 
and interventions developed through research over recent years that could benefit the care of their high-risk patients with oral feeding challenges.

\section{Caveats}

It is recognized that the knowledge we gained from our research will require confirmation via additional well-designed studies. However, the above proposed guidelines are based on the following justifications:

1. Preterm infants' difficulties in attaining safe and efficient oral feeding lead to prolonged NICU hospitalization, increased maternal stress, and medical costs. As such, the sooner they attain independent oral feeding safely and efficiently, the better.

2. Due to our limited understanding of the cause(s) leading to oral feeding difficulties, the current practices provided by feeding therapists lack evidence-based backing and consensus from team members as any benefit may be due to the infant's normal maturation.

3. In general, any new treatment/therapy requires additional well-designed studies to confirm and validate their efficacy. Insofar as our proposed guidelines address the care of individual infants rather than groups of infants, it is advanced that such approach may not be relevant. As mention earlier, we do not yet have the technology to determine the origination site(s) of an oral feeding problem in the Swallow Process and thus cannot identify the appropriate targeted intervention(s) to best treat them. For instance, if the adverse events observed on a particular patient originated at the "Safety" level, i.e., Respiration-Pharyngeal phase of swallowing (Figure 1), providing NNOMT treatment would likely not show any benefit. As such, providers need to remember that if a particular intervention is not efficacious for one infant, it can be for another as the cause(s) of their dysphagia may lie at different levels of the Swallow Process. This is the reason why in the proposed algorithm (Figure 6), a "trial and error approach" is used as different targeted interventions would be offered in two 2-day blocks, if no benefits are observed.

4. We speculate that the development of individualized management care plans that combine current feeding therapists' practices with the tools and interventions presented would lead to greater success for infants and the team members caring for them.

\section{CONCLUSION}

In summary, this report presents a review of the practices currently offered to NICU infants facing oral feeding challenges and the latest research that led to a number of efficacious evidence-based tools and interventions. It is recognized that "the underlying principles of the above model [will need further validation in order] to be clearly disseminated to practitioners of this field" (Research Model Innovations in Advancing Neonatal Care). However, it is hoped that in providing a greater understanding of the potential causes at the root of preterm infants' oral feeding difficulties, our research will improve the current clinical practice and assist "in the development of [additional] diagnostic tools and new therapies." This review presents a new perspective of how combining features of current practices with the use of novel tools/interventions could help practitioners improve their patients' care in developing structured and innovative management plans catered to the specific needs of individual patient. Additionally, it is proposed that a "Continuum of Care" approach may be envisaged whereby "feeders and growers" could be followed by out-patient clinical or home care services using the same technologies and methodologies. This would allow for earlier discharge, family reunion, and reduced medical cost for all.

\section{DATA AVAILABILITY STATEMENT}

The raw data supporting the conclusions of this article will be made available by the authors, without undue reservation, to any qualified researcher.

\section{ETHICS STATEMENT}

The studies involving human participants were reviewed and approved by The Baylor College of Medicine Institutional Review Board for Human Research. Parental consent was obtained following approval by attending neonatologists. Written informed consent to participate in this study was provided by the participants' legal guardian/next of kin.

\section{AUTHOR CONTRIBUTIONS}

CL is the primary investigator of the above series of studies and was involved in all aspects of the research, i.e., study designs, team members supervision, data collection, statistical analyses, and interpretations, preparation of manuscripts.

\section{FUNDING}

General Clinical Research Centers Program (NIHMO1RR000188): Oral/motor Kinetics in Neonates/Interventions for the enhancement of Oral Feeding in Preterm Infants (20002010); NIH Research Project Grant (NIH-R01 HD 44469): Oral Feeding in Infants (2005-2010), PI: CL; Co-I: L.E. Weisman, E.O. Smith, C. Redel; NIH Research Project Grant (NIH-R01 HD 28140): Feeding Strategies for Low Birth Weight Infants (19972001), PI: R.J. Schanler; Co-I: CL, K.J. Ellis, E.O. Smith, L.E. Weisman; NIH Research Project Grant (NIH-R01 HD 28140): Feeding Strategies for Low Birth Weight Infants (1992-1997); Co-PI's: R. J. Schanler, R. J. Shulman, CL, M. Heitkemper. 


\section{REFERENCES}

1. Benjasuwantep B, Chaithirayanon S, Eiamudomkan M. Feeding problems in healthy young children: prevalence, related factors and feeding practices. Pediatr Rep. (2013) 5:38-42. doi: 10.4081/pr.2013.e10

2. Han C, Shin J, Jeon GW. Development of swallowing function in infants with oral feeding difficulties. Int J Pediatr. (2020) 2020:5437376. doi: 10.1155/2020/5437376

3. Edwards L, Cotten CM, Smith PB, Goldberg R, Saha S, Das A, et al. Inadequate oral feeding as a barrier to discharge in moderately preterm infants. $J$ Perinatol. (2019) 39:1219-28. doi: 10.1038/s41372-019-0422-x

4. Bergman NJ, Ludwig R, Westrup B, Welch M. Nurturescience versus neuroscience: a case for rethinking perinatal mother-infant behaviors and relationship. Birth Defects Res. (2019) 111:1110-27. doi: 10.1002/bdr2.1529

5. A.A.o. Pediatrics. Hospital discharge of the high-risk neonate. Pediatrics. (2008) 122:1119-26. doi: 10.1542/peds.2008-2174

6. Lau C, Hurst N. Oral feeding in infants. Curr Probl Pediatr. (1999) 29:105-24. doi: 10.1016/S0045-9380(99)80052-8

7. Manuck TA, Rice MM, Bailit JL, Grobman WA, Reddy UM, Wapner RJ, et al. Preterm neonatal morbidity and mortality by gestational age: a contemporary cohort. Am J Obstet Gynecol. (2016) 215:103.e1-e14. doi: 10.1016/j.ajog.2016.01.004

8. Martin JA, Hamilton BE, Osterman MJK, Driscoll AK, Drake P. Births: final data for 2017. National vital statistics reports: from the Centers for Disease Control and Prevention, National Center for Health Statistics. Natl Vital Stat Syst. (2018) 67:1-50.

9. Olsen AL, Ammitzbøll J, Olsen EM, Skovgaard AM. Problems of feeding, sleeping and excessive crying in infancy: a general population study. Arch Dis Child. (2019) 104:1034-41. doi: 10.1136/archdischild-2019-316851

10. Lau C. Interventions to improve oral feeding performance of preterm infants. Perspect Swallow Swallow Disord. (2014) 23:23-45. doi: 10.1044/sasd23.1.23

11. Jadcherla SR, Challenges to eating, swallowing, and aerodigestive functions in infants: a burning platform that needs attention! J Pediatr. (2019) 211:7-9. doi: 10.1016/j.jpeds.2019.05.025

12. Lau C, Kusnierczyk I. Quantitative evaluation of infant's nonnutritive and nutritive sucking. Dysphagia. (2001) 16:58-67. doi: 10.1007/s004550000043

13. Lau C, Oral feeding in the preterm infant. NeoReviews. (2006) 7:e19-e27. doi: 10.1542/neo.7-1-e19

14. Lau C, Smith EO, Schanler RJ. Coordination of suck-swallow and swallow respiration in preterm infants. Acta Paediatr. (2003) 92:721-7. doi: 10.1111/j.1651-2227.2003.tb00607.x

15. Amaizu N, Shulman R, Schanler R, Lau C. Maturation of oral feeding skills in preterm infants. Acta Paediatr. (2008) 97:61-7. doi: 10.1111/j.1651-2227.2007.00548.x

16. Lau C, Alagugurusamy R, Schanler RJ, Smith EO, Shulman RJ. Characterization of the developmental stages of sucking in preterm infants during bottle feeding. Acta Paediatr. (2000) 89:846-52. doi: 10.1111/j.1651-2227.2000.tb00393.x

17. Rasch S, Sangild PT, Gregersen H, Schmidt M, Omari T, Lau C. The preterm piglet - a model in the study of esophageal development in preterm neonates. Acta Paediatr. (2010) 99:201-8 doi: 10.1111/j.1651-2227.2009. 01564.x

18. Rayyan M, Omari T, Debeer A, Allegaert K, Rommel N. Characterization of esophageal motility and esophagogastric junction in preterm infants with bronchopulmonary dysplasia. Neurogastroenterol Motil. (2020). doi: 10.1111/nmo.13849. [Epub ahead of print].

19. Arvedson JC, Lefton-Greif MA. Pediatric Videofluoroscopic Swallow Studies. A Profession Manual with Caregiver Guidelines. San Antonio, TX: Communication Skill Builders (1998).

20. Lau C, Development of suck and swallow mechanisms in infants. Ann Nutr Metab. 66(Suppl.) (2015) 5:7-14. doi: 10.1159/000381361

21. Martin-Harris B, McFarland D, Hill EG, Strange CB, Focht KL, Wan Z, et al. Respiratory-swallow training in patients with head and neck cancer. Arch. Phys Med Rehabil. (2015) 96:885-93. doi: 10.1016/j.apmr.2014.11.022

22. Lau C, Maturation of infant oral feeding skills. In: Ongkasuwan J, Chiou EH, editors, Pediatric Dysphagia - Challenges and Controversies. Switzerland: Springer Nature (2018). p. 17-32.
23. Bakewell-Sachs S, Medoff-Cooper B, Escobar GJ, Silber JH, Lorch SA. Infant functional status: the timing of physiologic maturation of premature infants. Pediatrics. (2009) 123:e878-e86. doi: 10.1542/peds.2008-2568

24. Smith GC, Gutovich J, Smyser C, Pineda R, Newnham C, Tjoeng TH, et al. Neonatal intensive care unit stress is associated with brain development in preterm infants. Ann. Neurol. (2011) 70:541-9. doi: 10.1002/ana.22545

25. Wolf LS, Glass RP. Feeding and Swallowing Disorders in Infancy: Assessment and Management, Therapy Skills Builders. Tucson, AZ: Therapy Skill Builders (1992).

26. Howe TH, Oromotor Therapy. In: Ongkasuwan J, Chiou EH, editors, Pediatric Dysphagia. Switzerland: Springer Nature (2018). p. 119-134.

27. Mitra S, Reid M, McDougall B, Johnston BC. Are neonatal clinical practice guidelines truly evidence-based? A case for incorporating family values and preferences. Acta Paediatr. (2019) 108:1564-6. doi: 10.1111/apa.14879

28. Lau C. Is there an advantage for preterm infants to feed orally in an upright or sidelying position? J Neonatal Nurs. (2013) 19:28-32. doi: 10.1016/j.jnn.2012.03.013

29. Lubbe W. Clinicians guide for cue-based transition to oral feeding in preterm infants: an easy-to-use clinical guide. J Eval Clin Pract. (2018) 24:80-8. doi: $10.1111 /$ jep. 12721

30. Watson J, McGuire W. Responsive versus scheduled feeding for preterm infants. Cochrane Database Syst Rev. (2016) CD005255. doi: 10.1002/14651858.CD005255.pub5

31. McGrattan KE, McFarland DH, Dean JC, Hill E, White DR, Martin-Harris B. Effect of single-use, laser-cut, slow-flow nipples on respiration and milk ingestion in preterm infants. Am J Speech Lang Pathol. (2017) 26:832-9. doi: 10.1044/2017_AJSLP-16-0052

32. Pados BF, Park J, Dodrill P. Know the flow: milk flow rates from bottle nipples used in the hospital and after discharge. Adv Neonatal Care. (2019) 19:32-41. doi: 10.1097/ANC.0000000000000538

33. N. Bell, C. Harding. An investigation of the flow rates of disposable bottle teats used to feed preterm and medically fragile infants in neonatal units across the UK in comparison with flow rates of commercially available bottle teats. Speech Lang Hear. (2019) 22:227-35. doi: 10.1080/2050571X.2019.1646463

34. Pados BF, Thoyre SM, Estrem HH, Park J, Knafl GJ, Nix B. Effects of milk flow on the physiological and behavioural responses to feeding in an infant with hypoplastic left heart syndrome. Cardiol Young. (2017) 27:139-53. doi: 10.1017/S1047951116000251

35. Lima AH, Cortes MG, Bouzada MC, Friche AA. Preterm newborn readiness for oral feeding: systematic review and meta-analysis. Codas. (2015) 27:101-7. doi: 10.1590/2317-1782/20152014104

36. Tian X, Yi LJ, Zhang L, Zhou JG, Ma L, Ou YX, et al. Oral motor intervention improved the oral feeding in preterm infants: evidence based on a meta-analysis with trial sequential analysis. Medicine. (2015) 94:e1310. doi: 10.1097/MD.0000000000001310

37. M. Brown Belfort. The science of breastfeeding and brain development. Breastfeed Med. (2017) 12:459-61. doi: 10.1089/bfm.2017.0122

38. Victora CG, Bahl R, Barros AJ, Franca GV, Horton S, Krasevec J, et al. Breastfeeding in the 21st century: epidemiology, mechanisms, lifelong effect. Lancet. (2016) 387:475-90. doi: 10.1016/S0140-6736(15)01024-7

39. Rollins NC, Bhandari N, Hajeebhoy N, Horton S, Lutter CK, Martines JC, et al. Why invest, and what it will take to improve breastfeeding practices? Lancet. (2016) 387:491-504. doi: 10.1016/S0140-6736(15)01044-2

40. Patel S, Patel S. The effectiveness of lactation consultants and lactation counselors on breastfeeding outcomes. J Hum Lact. (2016) 32:530-41. doi: $10.1177 / 0890334415618668$

41. Lau C. Breastfeeding challenges and the preterm mother-infant dyad: a conceptual model. Breastfeed Med. (2018) 13:8-17. doi: 10.1089/bfm.2016. 0206

42. Feldman R. The neurobiology of human attachments. Trends Cogn Sci. (2017) 21:80-99. doi: 10.1016/j.tics.2016.11.007

43. Penacoba C, Catala P. Associations between breastfeeding and motherinfant relationships: a systematic review. Breastfeed Med. (2019) 14:616-29. doi: 10.1089/bfm.2019.0106

44. Woolridge M. The biomechanics of breastfeeding: bridging the gap between engineering-based studies and clinical practice. Nestle Nutr Inst Workshop Ser. (2019) 90:13-32. doi: 10.1159/000490322 
45. Mezzacappa ES, Kelsey RM, Katkin ES. Breast feeding, bottle feeding, and maternal autonomic responses to stress. J Psychosom. Res. (2005) 58:351-65. doi: 10.1016/j.jpsychores.2004.11.004

46. Lau C. Effects of stress on lactation. Pediatr Clin North Am. (2001) 48:221-34. doi: 10.1016/S0031-3955(05)70296-0

47. Lau C, Hurst NM, Smith EO, Schanler RJ. Ethnic/racial diversity, maternal stress, lactation and very low birthweight infants. J Perinatol. (2007) 27:399408. doi: 10.1038/sj.jp.7211770

48. Raskovalova T, Teasley SL, Gelbert-Baudino N, Mauri PA, Schelstraete C, Massoutier M, et al. Breastfeeding assessment score: systematic review and meta-analysis. Pediatrics. (2015) 135:e1276-e85. doi: 10.1542/peds.2014-3072

49. Altuntas N, Kocak M, Akkurt S, Razi HC, Kislal MF. LATCH scores and milk intake in preterm and term infants: a prospective comparative study. Breastfeed Med. (2015) 10:96-101. doi: 10.1089/bfm.2014.0042

50. Gerçek E, Sarikaya Karabudak S, Ardiç Çelik N, Saruhan A. The relationship between breastfeeding self-efficacy and LATCH scores and affecting factors. $J$ Clin Nurs. (2017) 26:994-1004. doi: 10.1111/jocn.13423

51. Tuthill EL, McGrath JM, Graber M, Cusson RM, Young SL. Breastfeeding self-efficacy: a critical review of available instruments. J Hum Lact. (2016) 32:35-45. doi: 10.1177/0890334415599533

52. Ho Y-J, McGrath JM. A review of the psychometric properties of breastfeeding assessment tools. J Obstet Gynecol Neonatal Nurs. (2010) 39:386-400. doi: 10.1111/j.1552-6909.2010.01153.x

53. Perrella SL, Nancarrow K, Rea A, Murray K, Geddes DT, Simmer KN. Estimates of preterm infants' breastfeeding transfer volumes are not reliably accurate. Adv Neonatal Care. (2020). doi: 10.1097/ANC.0000000000000721. [Epub ahead of print].

54. White-Traut R, Rankin K, Lucas R, Shapiro N, Liu L, Medoff-Cooper B. Evaluating sucking maturation using two pressure thresholds. Early Hum Dev. (2013) 89:833-7. doi: 10.1016/j.earlhumdev.2013.07.026

55. Sameroff AJ. The components of sucking in the human newborn. J Exp. Child Psychol. (1968) 6:607-23. doi: 10.1016/0022-0965(68)90106-9

56. Tarrant SC, Ellis RE, Flack FC, Selley WG. Comparative review of techniques for recording respiratory events at rest and during deglutition. Dysphagia. (1997) 12:24-38. doi: 10.1007/PL00009515

57. Lau C, Schanler RJ. Oral motor function in the neonate. Clin Perinatol. (1996) 23:161-78. doi: 10.1016/S0095-5108(18)30236-7

58. Mayerl CJ, Gould FDH, Bond LE, Stricklen BM, Buddington RK, German RZ. Preterm birth disrupts the development of feeding and breathing coordination. J Appl Physiol. (2019) 126:1681-6. doi: 10.1152/japplphysiol.00101.2019

59. Sanghavi R, Rosen R. Esophageal Dysplagia. In: Ongkasuwan J, Chiou EH, editors, Pediatric Dysphagia. Switzerland: Springer Nature, Switzerland (2018). p. 215-38.

60. Sangild PT. Gut responses to enteral nutrition in preterm infants and animals. Exp. Biol Med (Maywood). (2006) 231:1695-711. doi: $10.1177 / 153537020623101106$

61. Omari TI, Savilampi J, Kokkinn K, Schar M, Lamvik K, Doeltgen S, et al. The reliability of pharyngeal high resolution manometry with impedance for derivation of measures of swallowing function in healthy volunteers. Int. J Otolaryngol. (2016) 2016:2718482. doi: 10.1155/2016/ 2718482

62. Rommel N, Omari TI, Selleslagh M, Kritas S, Cock C, Rosan R, et al. High-resolution manometry combined with impedance measurements discriminates the cause of dysphagia in children. Eur. J Pediatr. (2015) 174:1629-37. doi: 10.1007/s00431-015-2582-9

63. Prabhakar V, Hasenstab KA, Osborn E, Wei L, Jadcherla SR. Pharyngeal contractile and regulatory characteristics are distinct during nutritive oral stimulus in preterm-born infants: Implications for clinical and research applications. Neurogastroenterol Motil. (2019) 31:e13650. doi: $10.1111 / \mathrm{nmo} .13650$

64. Li Z-H, Wang D-H, Dong M, Ke M-Y, Wang Z-F. Clinical application of high resolution manometry for examining esophageal function in neonates. Zhongguo Dang Dai Er Ke Za Zhi. (2012) 14:607-11.

65. Rayyan M, Omari T, Abu-Assi R, Allegaert K, Rommel N. Effect of esophageal length on high-resolution manometry metrics: extension to the neonatal population. Neurogastroenterol Motil. (2020) 32:e13800. doi: $10.1111 / \mathrm{nmo} .13800$
66. Wolff PH. The serial organization of sucking in the young infant. Pediatrics. (1968) 42:943-56

67. Lau C, Smith EO. A novel approach to assess oral feeding skills of preterm infants. Neonatology. (2011) 100:64-70. doi: 10.1159/000321987

68. Lau C, Bhat K, Potak DC, Schanler RJ. Oral feeding assessment predicts length of hospital stay in late preterm infants. J Pediatr Mother Care. (2015) 1:102. doi: 10.19104/japm.2016.102

69. Lau C, Schanler RJ. Oral feeding in premature infants: advantage of a self-paced milk flow. Acta Paediatr. (2000) 89:453-9. doi: 10.1111/j.1651-2227.2000.tb00083.x

70. Lau C, Fucile S, Schanler RJ. A self-paced oral feeding system that enhances preterm infants' oral feeding skills. J Neonat Nurs. (2015) 21:121-6. doi: 10.1016/j.jnn.2014.08.004

71. Tanaka S, Kogo M, Chandler SH, Matsuya T. Localization of oral-motor rhythmogenic circuits in the isolated rat brainstem preparation. Brain Res. (1999) 821:190-9. doi: 10.1016/S0006-8993(99)01117-8

72. Jean A. Brain stem control of swallowing: neuronal network and cellular mechanisms. Physiol Rev. (2001) 81:929-69. doi: 10.1152/physrev.2001. 81.2.929

73. Delafield-Butt JT, Freer Y, Perkins J, Skulina D, Schogler B, Lee DN Prospective organization of neonatal arm movements: a motor foundation of embodied agency, disrupted in premature birth. Dev Sci. (2018) 21:e12693. doi: 10.1111/desc. 12693

74. Craig CM, Grealy MA, Lee DN. Detecting motor abnormalities in preterm infants. Exp. Brain Res. (2000) 131:359-65. doi: 10.1007/s002219900227

75. Craig CM, Lee DN. Neonatal control of nutritive sucking pressure: evidence for an intrinsic tau-guide. Exp Brain Res. (1999) 124:371-82. doi: $10.1007 / \mathrm{s} 002210050634$

76. McFarland DH, Tremblay P. Clinical implications of cross-system interactions. Semin. Speech Lang. (2006) 27:300-9. doi: 10.1055/s-2006955119

77. Barlow SM, Estep M. Central pattern generation and the motor infrastructure for suck, respiration, and speech. J Commun. Disord. (2006) 39:366-80. doi: 10.1016/j.jcomdis.2006.06.011

78. White-Traut RC, Berbaum ML, Lessen B, McFarlin B, Cardenas L. Feeding readiness in preterm infants: the relationship between preterm behavioral state and feeding readiness behaviors and efficiency during transition from gavage to oral feeding. MCN Am J Matern Child Nurs. (2005)30:52-9.

79. Gill NE, Behnke M, Conlon M, Anderson GC. Nonnutritive sucking modulates behavioral state for preterm infants before feeding. Scand J Caring Sci. (1992) 6:3-7. doi: 10.1111/j.1471-6712.1992.tb00115.x

80. Als $\mathrm{H}, \mathrm{A}$ synactive model of neonatal behavior organization: framework for the assessment of neurohehavioral development in the preterm infant and for support of infants and parents in the neonatal intensive care environment. Phys Occup Ther Pediatr. (1986) 6:3-55. doi: 10.1080/J006v06n03 02

81. DeArmond AC, Yello JR, Bubshait KS, Krueger CA. Revisiting sound in the NICU: implications for the developmental timing, amount and type of sound. Pediatr Neonatal Nurs. (2016) 2. doi: 10.16966/2470-0983.116

82. Moore ER, Bergman N, Anderson GC, Medley N. Early skin-to-skin contact for mothers and their healthy newborn infants. Cochrane Database Syst Rev. (2016) 11:CD003519. doi: 10.1002/14651858.CD003519.pub4

83. Conde-Agudelo A, Diaz-Rossello JL. Kangaroo mother care to reduce morbidity and mortality in low birthweight infants. Cochrane Database Syst Rev. (2016) CD002771. doi: 10.1002/14651858.CD002771.pub4

84. Bieleninik L, Ghetti C, Gold C. Music Therapy for preterm infants and their parents: a meta-analysis. Pediatrics. (2016) 138:e20160971. doi: 10.1542 /peds.2016-0971

85. Field T. Massage therapy for infants and children. J Dev Behav Pediatr. (1995) 16:105-111. doi: 10.1097/00004703-199504000-00008

86. Leleu A, Rekow D, Poncet F, Schaal B, Durand K, Rossion B, et al. Maternal odor shapes rapid face categorization in the infant brain. Dev Sci. (2020) 23:e12877. doi: 10.1111/desc. 12877

87. Lau C, Fucile S, Gisel EG. Impact of nonnutritive oral motor oral stimulation and infant massage on oral feeding skills in preterm infants. J Neonatal Perinatol Med. (2012) 5:311-7. doi: 10.3233/NPM-1262612

88. Fucile S, Gisel E, Lau C. Oral stimulation accelerates the transition from tube to oral feeding in preterm infants. J. Pediatr. (2002) 141:230-6. doi: $10.1067 / \mathrm{mpd} .2002 .125731$ 
89. Lau C, Smith E. Interventions to improve the oral feeding performance of preterm infants. Acta Paediatr. (2012) 101:e269-e74. doi: 10.1111/j.1651-2227.2012.02662.x

90. Pados BF, McGlothen-Bell K. Benefits of infant massage for infants and parents in the NICU. Nurs Womens Health. (2019) 23:265-71. doi: 10.1016/j.nwh.2019.03.004

91. Niemi AK. Review of randomized controlled trials of massage in preterm infants. Children (Basel, Switzerland). (2017) 4:21. doi: 10.3390/children4040021

92. Field T, Schanberg SM, Scafidi F, Bauer CR, Vega-Lahr N, Garcia R, et al. Tactile/kinesthetic stimulation effects on preterm neonates. Pediatrics. (1986) 77:654-8.

93. Nudo RJ, Wise BM, SiFuentes F, Milliken GW. Neural substrates for the effects of rehabilitative training on motor recovery after ischemic infarct. Science. (1996) 272:1791-4. doi: 10.1126/science.272.526 9.1791

94. Byl NN, Merzenich MM, Cheung S, Bedenbaugh P, Nagarajan SS, Jenkins WM. A primate model for studying focal dystonia and repetitive strain injury: effects on the primary somatosensory cortex. Phys Ther. (1997) 77:269-84. doi: $10.1093 / \mathrm{ptj} / 77.3 .269$

95. Als H. Toward a synactive theory of development: promise for the assessent and support of infant individuality. Infant Ment Health J. (1982) 3:22943. doi: 10.1002/1097-0355(198224)3:4<229::AID-IMHJ2280030405>3. $0 . \mathrm{CO} ; 2-\mathrm{H}$
96. Als H. A manual for naturalistic observation of the newborn (preterm and full term infants). In: Goldson E, editor, Nurturing the Premature Infant, Developmental Interventions in the Neonatal Intensive Care Nursery. New York, NY: Oxford University Press (1995). p. 77-85.

97. Vandenberg KA. Individualized developmental care for high risk newborns in the NICU: a practice guideline. Early Hum Dev. (2007) 83:433-42. doi: 10.1016/j.earlhumdev.2007.03.008

98. Roué J-M, Kuhn P, Lopez Maestro M, Maastrup RA, Mitanchez D, Westrup B, et al. Eight principles for patient-centred and family-centred care for newborns in the neonatal intensive care unit. Arch Dis Child Fetal Neonatal Ed. (2017) 102:F364-F8. doi: 10.1136/archdischild-2016-312180

99. Macho P. Individualized developmental care in the NICU: a concept analysis. Adv Neonatal Care. (2017) 17:162-74. doi: 10.1097/ANC.0000000000000374

Conflict of Interest: The author declares that the research was conducted in the absence of any commercial or financial relationships that could be construed as a potential conflict of interest.

Copyright (c) 2020 Lau. This is an open-access article distributed under the term of the Creative Commons Attribution License (CC BY). The use, distribution or reproduction in other forums is permitted, provided the original author(s) and the copyright owner(s) are credited and that the original publication in this journal is cited, in accordance with accepted academic practice. No use, distribution or reproduction is permitted which does not comply with these terms. 